\title{
Effects of Oven-Drying on the Viscosity of Okra(Abelmoschus Esculentus)
}

\section{BurubaiW* and Amber B}

Department of Agricultural\& Environmental Engineering,Faculty of Engineering, Niger Delta University,P.M.B 071

Wilberforce Island, Yenagoa, Bayelsa State, Nigeria

\begin{abstract}
The effects of drying on the viscosity of Okra (Abelmoschus esculentus) fruit were evaluated, using a falling ball viscometer. Results show that, at $95 \%$ confidence level, drying had a significant influence on viscosity, density and Reynolds number of Okra suspension. Viscosity values obtained ranged from $0.34 \mathrm{cP}$ to $0.972 \mathrm{cP}$ for dried Okra as against $0.676 \mathrm{cP}$ to $2.84 \mathrm{cP}$ for the fresh Okra at corresponding mixing concentrations of $100 \mathrm{~g}$ to $400 \mathrm{~g}$ respectively. This implies that, glycan, which is responsible for the viscosity of Okra reduces in quality as Okra is dried. Therefore, the hypothesis that okra suspension either fresh or dried would obey stokes law was verified.
\end{abstract}

Keywords: Drying; Fall velocity; Fall time; Reynolds number; okra; Viscosity

\section{Introduction}

Okra (Abelmoschus esculentus) is one of the most widely consumed and deliberately cultivated vegetables known to mankind. It is scientifically proven to be rich in energy, protein, niacin, ascorbic acid, calcium and other vitamins [1]. The amino acid composition of Okra seed protein discovered to be similar to that of Soybean [2]. The high percentage of linoleic acid (42\%) makes Okra seed oil desirable and the amino acid pattern of the protein renders it an adequate supplement to legume or cereal-based diets [3-5]. This nutritious vegetable thrives well in both temperate and tropical countries. Thus, Nigeria, India, Pakistan, Egypt and Ghana are the leading producers of Okra worldwide.

Okra is cherished in the African cuisine because of its soup making characteristics which is scientifically called viscosity. The viscosity of aqueous Okra suspension and the gum-like consistency which is desirable in soup is as a result of the presence of a chemical substance called glycan [6]. However, being an agricultural produce, Okra is highly perishable and seasonal, and to make it available all year round, several preservation methods has been adopted. This includes slicing the Okra fruit and sun drying until brittleness is attained [7]. The sundried product is then milled into powder for future use. Although sundrying may be cheap, its drawbacks are well documented in literature $[8,9]$. They therefore recommended solar or hot-air drying as the best preservation methods. However, the effects of these preservation methods on the viscosity of Okra need to be desired because the viscosity of foods determines mouth feel, ease of swallowing, pourability and pumping needs. It is therefore the objective of this study to evaluate the effect of oven-drying on the viscosity of Okra using a falling ball viscometer.

\section{Materials and Methods}

\section{Sample preparations}

Freshly harvested Okra (Abelmoschus esculentus) fruits were purchased from the Amassoma market in Bayelsa State, Nigeria, in November, 2012. All foreign materials were sorted out and the remnant sliced and divided into 3 groups (A, B and C). Each group containing $300 \mathrm{~g}$ of sliced Okra fruits were then placed on flat plate sample holders and dried in the hot air oven dryer at 600C. The samples were weighed at regular intervals with a Camry Digital scale (EK 5350) until a constant weight was achieved in all samples at 1hour and 20 minutes. The moisture content for the 3 samples were then determined and the average recorded. The dried Okra were then grinded into powder using mortar and pestle and stored in a polyethylene bag to prevent hygroscopic tendencies. Then, the remaining undried fresh Okra fruits weighing $900 \mathrm{~g}$ were also grinded using same mortar in preparation for the analysis proper.

\section{Theory of falling ball viscometer}

Falling ball viscometers are simple long vertical tubes with sufficient diameter to permit the fall under gravity of a spherical ball. They operate on the fundamental principle of measuring the time for a ball to fall through the liquid under gravity. The falling ball is subjected to gravitational force, drag force and buoyancy force as displayed in the free body diagram below.

FD

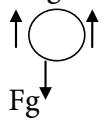

Balancing the forces, we get

Gravitational force $\left(\mathrm{F}_{\mathrm{g}}\right)=$ Drag force $\left(\mathrm{F}_{\mathrm{D}}\right)+$ Buoyancy force $\left(\mathrm{F}_{\mathrm{B}}\right)$ ................... (1)

$$
\frac{\pi D_{p}^{3} \rho_{p} g}{6}=\frac{\pi D_{p}^{3} \rho_{f} g}{6}+C_{d} \pi D_{p}^{2} \rho_{f} V^{2}
$$

$$
\begin{array}{ll}
D_{\mathrm{P}} & =\text { Diameter of the ball }(\mathrm{m}) \\
\rho_{\mathrm{P}} & =\text { Density of the ball }(\mathrm{kg} / \mathrm{m} 3) \\
\rho_{\mathrm{f}} & =\text { Density of the fluid }(\mathrm{kg} / \mathrm{m} 3) \\
\mathrm{C}_{\mathrm{d}} & =\text { Drag coefficient } \\
\mathrm{V} & =\text { Velocity of the ball, } \mathrm{m} / \mathrm{s}
\end{array}
$$

*Corresponding author: :Burubai W, Department of Agricultural\& Environmental Engineering, Faculty of Engineering, Niger Delta University, P.M.B 071 Wilberforce Island, Yenagoa, Bayelsa State, Nigeria, Tel: (800)555-1212; Email: ebiburu@yahoo.com

Received September 12, 2013; Accepted December 10, 2013; Published December 30, 2013

Citation: Burubai W, Amber B (2013) Effects of Oven-Drying on the Viscosity of Okra (Abelmoschus Esculentus). J Food Process Technol 4: 287. doi:10.4172/21577110.1000287

Copyright: (c) 2013 Burubai W, et al. This is an open-access article distributed under the terms of the Creative Commons Attribution License, which permits unrestricted use, distribution, and reproduction in any medium, provided the original author and source are credited. 
$\mathrm{t} \quad=$ Time, $\mathrm{s}$

At equilibrium during the fall (at stokes region), we get

$\frac{d v}{d t}=0$

This implies that, drag coefficient, $C_{d=} \frac{24}{\mathrm{Re}}$

Where Reynolds number, Re is

$\operatorname{Re}=D_{p} \rho_{f} V / \mu$

And $\mu=$ Viscosity

Substituting into equation (2) we get

$\frac{\pi D_{p}^{3} \rho_{p} g}{6}=\frac{\pi D_{p}^{3} \rho_{f} g}{6}+\frac{6 \pi D_{p} \mu V}{2}$

Solving we get

Viscosity, $\mu=\frac{2 r^{2}\left(\rho_{p}-\rho_{f}\right) g}{9 V}$

Therefore, it is possible to determine the dynamic viscosity of the Okra mixture if the terminal velocity of the falling ball is calculated.

\section{Procedure}

Using a Digital Caliper, the diameter of the spherical ball was determined, and result divided by 2 to obtain the radius of the ball. The ball density was then determined by measuring its mass and volume. The dried Okra powder was then mixed with water at $1000 \mathrm{C}$ in the following ratios based on the available equipment size;

$100 \mathrm{~g}$ of Okra powder: $1000 \mathrm{ml}$ of water

$200 \mathrm{~g}$ of Okra powder: $1000 \mathrm{ml}$ of water

$300 \mathrm{~g}$ of Okra powder: $1000 \mathrm{ml}$ of water

$400 \mathrm{~g}$ of Okra powder: $1000 \mathrm{ml}$ of water

These mixing ratios were repeated for the freshly blended Okra paste, and the mixturesvigorously stirred and separately put into a $2000 \mathrm{ml}$ graduated cylinder of known length and diameter. A convenient starting point of $5 \mathrm{~cm}$ below the surface of the liquid and ending point of $5 \mathrm{~cm}$ above the bottom was marked to ensure the stokes region. The distance between the starting and ending points was measured with a calibrated plastic ruler and the result called the "fall distance". The spherical ball was then dropped and the stopwatch started immediately the ball crossed the starting point, and stopped immediately it crossed the ending point. The fall time which is the time taken for the ball to fall through the fall distance was recorded. The density of the Okra mixture was then determined and the velocity of fall calculated. This procedure was repeated for all mixing ratios for both the dried and fresh Okra and the data plugged into the respective equations to obtain the desired parameters. This procedure was also applied by various authors for different fluids [10-12].

\section{Results and Discussions}

A summary of the measured and determined parameter are presented in (Tables 1and 2).

\section{Effect of drying on density of mixture}

As shown in (Table 2), the density of the dried Okra mixture changed from $0.93 \mathrm{~g} / \mathrm{cm}^{3}$ to $1.87 \mathrm{~g} / \mathrm{cm}^{3}$ for a mixing ratio of $100 \mathrm{~g}$ to $400 \mathrm{~g}$ per $1000 \mathrm{ml}$ of water respectively. However, for fresh Okra at the same mixing ratio, density changed from $0.95 \mathrm{~g} / \mathrm{cm}^{3}$ to $2.27 \mathrm{~g} / \mathrm{cm}^{3}$. Figure 1 reveals the graphical behaviour of density for both the dried and fresh Okra mixture as the concentration (grams) increased. It shows a polynomial relationship exist between density values of dried and fresh Okra against mixing ratios. These density values are comparable to those of milk $\left(1.02-1.05 \mathrm{~g} / \mathrm{cm}^{3}\right)$ and olive oil $\left(0.92 \mathrm{~g} / \mathrm{cm}^{3}\right)$

\section{Effect of drying on ball fall time}

The ball fall time for the various mixtures of dried and fresh Okra is indicated in Table 2. It is evident from data provided that, fall time increased as the quantity of Okra added increases in both cases.

For the dried Okra and at a mixture of $100 \mathrm{~g}$, a fall time of 5 seconds was noted. The fall time then increased to 18.32 seconds at $400 \mathrm{~g}$ mixture. In like manner, a fall of 10 seconds was observed for fresh okra at a mixture of $100 \mathrm{~g}$, but later increased to 51.32 seconds at a mixture of $400 \mathrm{~g}$. This behaviour, which is similar in both cases, could be attributed to density difference in the various mixing ratios. More so, a plot of the means of the fall time for both cases was conducted and results (Figure 2) show that polynomial models exist for the fall time between the dried and fresh Okra and mixing ratios. Results obtained here agree with the findings of other scientist on the ball fall time for sucrose solution [10].

\begin{tabular}{|c|c|c|}
\hline $\mathbf{S} / \mathbf{N}$ & Parameter & Values \\
\hline $\mathbf{1}$ & Spherical ball diameter & $0.9 \mathrm{~cm}$ \\
\hline $\mathbf{2}$ & Spherical ball weight & $2 \mathrm{~g}$ \\
\hline $\mathbf{3}$ & Spherical ball volume & $0.382 \mathrm{~cm}^{3}$ \\
\hline $\mathbf{4}$ & Height of graduated cylinder & $38 \mathrm{~cm}$ \\
\hline $\mathbf{5}$ & Diameter of cylinder & $6.7 \mathrm{~cm}$ \\
\hline $\mathbf{6}$ & Density of spherical ball & $5.24 \mathrm{~g} / \mathrm{cm}^{3}$ \\
\hline $\mathbf{7}$ & Weight of empty beaker & $41 \mathrm{~g}$ \\
\hline $\mathbf{8}$ & Fall distance & $28 \mathrm{~cm}$ \\
\hline
\end{tabular}

*Moisture contents of samples A,B andC were $9.92,10.1$ and $10.1 \%$ respectively Table 1: Measured parameters.

\begin{tabular}{|l|c|c|c|l|l|l|l|}
\hline & \multicolumn{3}{|c|}{ Dried Okra } & \multicolumn{3}{l|}{ Fresh Okra } \\
\hline & $100 \mathrm{~g}$ & $200 \mathrm{~g}$ & $300 \mathrm{~g}$ & $400 \mathrm{~g}$ & $100 \mathrm{~g}$ & $200 \mathrm{~g}$ \\
\hline Densityof mixture & $0.93 \pm 0.01$ & $0.95 \pm 0.1$ & $1.43 \pm 0.05$ & $1.87 \pm 0.1$ & $0.95 \pm 0.9$ & $1.03 \pm 0.1$ & $1.55 \pm 0.2$ \\
\hline Fall time (s) & $5 \pm 0.3$ & $7 \pm 0.5$ & $10.63 \pm 1.3$ & $18.32 \pm 0.6$ & $10 \pm 1.4$ & $15 \pm 0.5$ & $29.44 \pm 0.7$ \\
\hline $\begin{array}{l}\text { Fall velocity } \\
(\mathrm{cm} / \mathrm{s})\end{array}$ & $5.6 \pm 0.02$ & $4 \pm 0.7$ & $2.63 \pm 0.04$ & $1.53 \pm 0.2$ & $2.8 \pm 0.6$ & $1.8 \pm 0.4$ & $0.95 \pm 0.9$ \\
\hline Viscosity (cP) & $0.34 \pm 0.06$ & $0.47 \pm 0.63$ & $0.63 \pm 0.1$ & $0.97 \pm 0.04$ & $0.67 \pm 0.1$ & $0.99 \pm 0.1$ & $1.83 \pm 1.3$ \\
\hline Reynolds number & $100.63 \pm 3.1$ & $53.7 \pm 2.5$ & $40.05 \pm 2.8$ & $19.72 \pm 1.2$ & $52.73 \pm 0.3$ & $12.98 \pm 3.0$ & $5.37 \pm 1.4$ \\
\hline
\end{tabular}

Table 2: Experimentally determined parameters. 


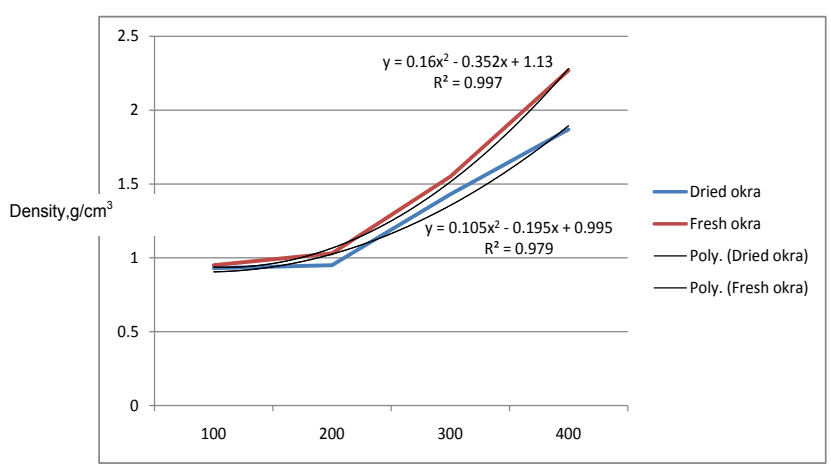

Mixing ratio (g/1000ml)

Figure 1: Effect of drying on the density of okra

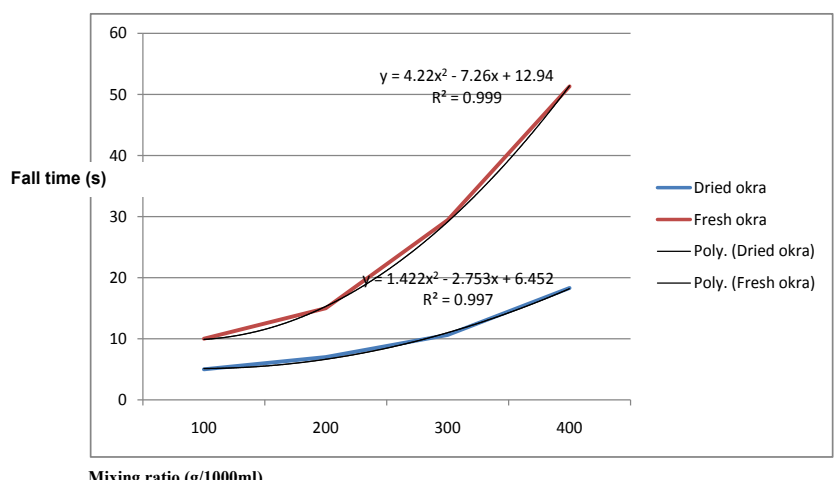

Figure 2: Effect of drying on the ball fall time.

\section{Effect of drying on fall velocity}

The fall velocity which is otherwise called the terminal velocity, atstoke's region, tends to decrease as the mixing ratio increased for both dried and fresh Okra. At a mixture of $100 \mathrm{~g}$ dried Okra, a fall velocity of $5.6 \mathrm{~cm} / \mathrm{s}$ was recorded. This value then decreased to $1.53 \mathrm{~cm} / \mathrm{s}$ at $400 \mathrm{~g}$ dried Okra mixture. Similarly, for fresh Okra, a fall velocity of $2.8 \mathrm{~cm} / \mathrm{s}$ was obtained at a mixture of $100 \mathrm{~g}$ and $0.55 \mathrm{~cm} / \mathrm{s}$ at $400 \mathrm{~g}$ mixture. This decrease in fall velocity which is more noticeable in fresh Okra may be as a result of both density and concentration differences. A plot of fall velocity values of both dried and fresh Okra as against mixing ratios is indicated in Figure 3 and the attendant relationship between both appears polynomial. The observations made tend to concur with the findings of other authors $(11,12)$.

\section{Effect of drying on viscosity}

Viscosity, which is the desired parameter, is one of the fundamental qualities that characterize flow behavior. It is, indeed, a measure of a fluid's ability to resist motion when a shearing stress is applied. Data from(Table 2) shows that viscosity, generally, increased with increase in mixing ratio for both dried and fresh Okra. For dried Okra and at $100 \mathrm{~g}$ mixture, a $0.34 \mathrm{cP}$ was recorded. But this viscosity value increased to $0.97 \mathrm{cP}$ at $400 \mathrm{~g}$ mixture. A similar behavior was noted for fresh Okra as viscosity changed from $0.67 \mathrm{cP}$ to $2.84 \mathrm{cP}$ at $100 \mathrm{~g}$ and $400 \mathrm{~g}$ mixtures respectively. This implies that the fresh Okra mixtures are more viscous and could be as a result of the unaltered viscosity prompting chemical called glycan. The presence of glycan tends to increase the cohesive forces between molecules. However, the dry Okra mixtures showed lower viscosities at the various mixing ratios implying that glycan content was drastically reduced in the drying process. Results from a statistical analysis conducted on viscosities of both dried and fresh Okra mixtures showed a significant difference at 95\% confidence levels. A graphical behavior of viscosity with mixing ratios for both cases as indicated in Figure 4 agrees with the works of $[13,14]$ and also similar to the viscosities of milk $\left(2.0 \mathrm{~g} / \mathrm{cm}^{3}\right)$ and cocoa butter $\left(0.5 \mathrm{~g} / \mathrm{cm}^{3}\right)$

\section{Effect of drying on Reynolds Number}

Reynolds number is a dimensionless parameter that is used to indicate the degree of turbulence in a flow regime. Information provided in Table 2 shows that, Reynolds number generally decreased with increase in mixing ratio for both dried and fresh Okra. At $100 \mathrm{~g}$ mixture of dried Okra, a Reynolds number of 102.63 were achieved. This value then decreased to 19.72 at a corresponding mixing ratio of 400g. A similar negative trend was observed for fresh Okra as Reynolds number decreased from 52.73 to 2.92 at the respective mixing ratios of $100 \mathrm{~g}$ and $400 \mathrm{~g}$. Results therefore reveal that, Reynolds number observed in fresh Okra was by far lower than those of dried Okra. This could be as a result of the high glycan content in fresh Okra, which is known to boost the resistance to flow.A plot conducted for Reynolds numbers of both cases shows that a logarithmic relationship exists between dried okra and mixing ratio. For fresh okra, a power series tends to dominate in the relationship as revealed in Figure 5. These findings are in concord with those of authors [12].

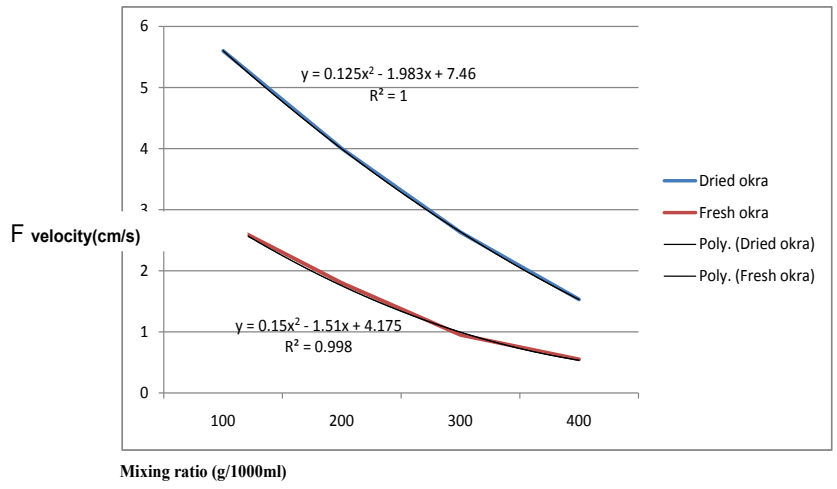

Figure 3: Effect of drying on fall velocity.

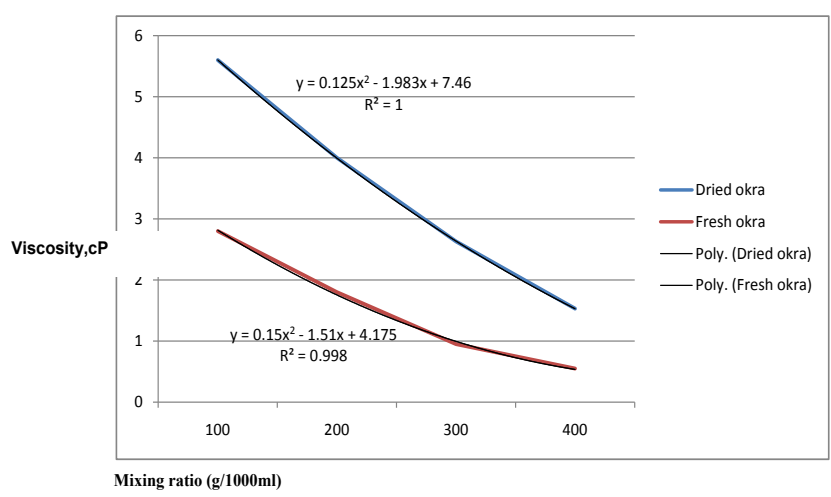

Figure 4: Effect of drying on viscosity of okra. 
Citation: Burubai W, Amber B (2013) Effects of Oven-Drying on the Viscosity of Okra (Abelmoschus Esculentus). J Food Process Technol 4: 287. doi:10.4172/2157-7110.1000287

Page 4 of 4

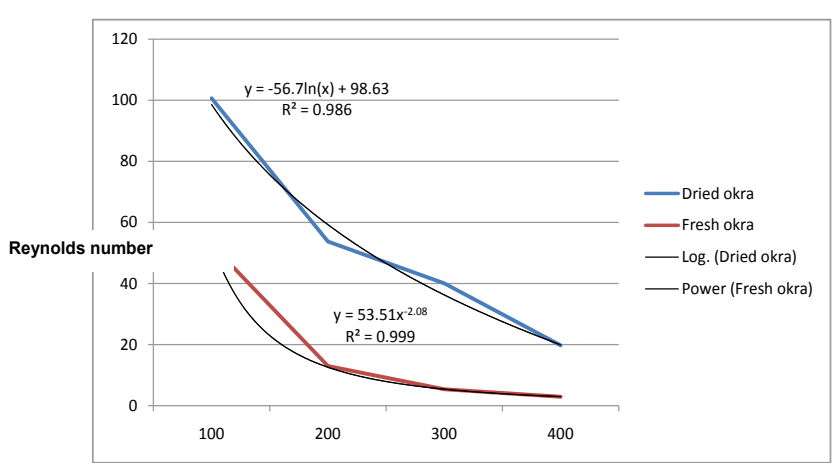

Mixing ratio (g/1000ml)

Figure 5: Effect of drying on Reynolds number of okra suspension.

\section{Conclusions}

The effects of oven-drying on some flow characteristics of Okra were evaluated. Data shows that viscosity, density and fall time were significantly reduced by drying. Conversely, Reynolds number and ball fall velocity were found to increase as Okra is dried and grinded to powder.

\section{Acknowledgment}

The authorswish to thank the staff of the Food Process Engineering laboratory of the Niger Delta University, Wilberforce Island, Bayelsa State, Nigeria for their assistance while the study lasted.

\section{References}

1. Adetuyi FO, Osagie AU,Adekunle AT (2011) Nutrient, antinutrient, mineral and zinc bioavailability of okra Abelmoschus esculentus (L) Moench Variety. Am J FoodNutri 1:49-54
2. Karakottsides PA, ConstantinidesSM(1975) Okra seeds, a new protein source J Agric FoodChem 23: 10-24.

3. Savello PA, Martin FW, Hill JM(1980) Nutritional Composition of Okra seed meal. J Agric FoodChem 28: 1163-1166.

4. Calisir S, Ozcan M, Haciseferogullari H, Ugur YM (2005) A study on some physico - chemical properties of Turkey Okra (Hibiscus esculenta L.) seeds. J Food Eng 68: 73-78.

5. Adom KK, Dzogbefia VP, Elis WO (1996) Solar drying of Okra: Effects of selected packaging materials on storage stability. Food Res 7: 589-593.

6. Owoye S(1990) Chemical properties of Okra. J of Tropical Fruits 3: 100 - 104.

7. Kordylas $\mathrm{JM}(1991)$ Processing and preservation of tropical and subtropical foods. J Food Sci 51: 123-628.

8. Doymaz I(2005) Drying characteristics and Kinetics of Okra. J Food Eng 69 275-279.

9. Addoh AA (1983) Ascorbic acid contents of foods consumed in the Northern State of Nigeria. NIFOJ1:129-132

10. Evelyn C, Julia G, Bella G(2012) Investigation of falling ball viscometry and its accuracy.Laboratory Report.

11. FludeMJC, Daborn JE (1982) Viscosity measurements by means of falling spheres compared with capillary viscometer. J Phys 15:557-563.

12. Amit S, Sharma L, Pinakig(2012) Studies on falling ball viscometry. Master Degree Thesis .Depertment of Chemistry, Indian Instituteof Technology, Kanpur,India.

13. KobbekaduwaK,Wijayaratna W (2012) Data Acquisition System for a FallingSphere Viscometer.Proceedings of the Technical Sessions. Institute of PhysicsSri Lanka 28: 45-53.

14. Eze Jl, Akubor PI (2012) Effect of drying methods and storage on the physicochemical properties ofokra. J Food Process Technology 3: 1-4. 